\title{
Coronary blood flow and myocardial ischaemia in hypertension
}

\author{
F. Magrini ${ }^{\mathrm{a}, *}$, M. Ciulla ${ }^{\mathrm{b}}$, P. Vandoni ${ }^{\mathrm{b}}$, R. Paliotti $^{\mathrm{b}}$ \\ ${ }^{a}$ Cattedra di Medicina Interna, Università di Cagliari, Cagliari, Italy \\ b Istituto Clinica Medica Generale e Terapia Medica, Università di Milano, Centro di Fisiologia Clinica e Ipertensione, Ospedale \\ Maggiore di Milano, Via F. Sforza 35, 20122 Milan, Italy
}

\begin{abstract}
The aim of this investigation was to study the coronary pressure-flow relationship in 60 patients with chronic arterial hypertension of diverse aetiologies and in 14 normotensive subjects (control group). The hypertensive cohort included 6 patients with isolated systolic hypertension (ISH), 7 renovascular hypertensive patients with abnormally elevated angiotensin II plasma levels but without electrocardiographic and/or echocardiographic evidence of left ventricular hypertrophy (LVH) and 47 subjects with essential hypertension (EH), 21 of whom had LVH by electrocardiogram and/or echocardiogram. In the hypertensive cohort a Frank-Starling-like curve was found to describe the coronary pressure-flow relationship when the baseline values for coronary sinus blood flow (CBF, intravascular Doppler technique) were plotted against mean aortic pressure (intra-arterial blood pressure). In particular, the descending limb of such a curve represented a critical region where CBF was "inappropriately" low with respect to perfusion pressure. It was thus concuded that this inability of the heart to adapt CBF to its needs might account for the higher propensity to develop myocardial ischaemia encountered in severe essential hypertensive subjects with concomitant LVH and renovascular hypertensive patients.
\end{abstract}

Keywords: Hypertension; Coronary circulation; Angiotensin; Left ventricular hypertrophy; Ischaemic heart disease

\section{Introduction}

There is overwhelming epidemiological and experimental evidence confirming the importance of established arterial hypertension as a major risk factor for stroke, renal disease and ischaemic heart disease [1-8]. In particular, long-standing hypertension is known to interfere with myocar-

\footnotetext{
* Corresponding author. Centro di Fisiologia Clinica e Ipertensione, Via S. Sforza 35, 20122 Milan, Italy. Tel.: (+392) 55033523 ; fax: $(+39-2) 5457666$.
}

Elsevier Science B.V.

SSDI 0300-2977(95)00063-1 dial perfusion by both accelerating atherosclerosis [9], thus promoting obstructive coronary lesions, and inducing qualitative abnormalities in coronary haemodynamics, whether they are associated with left ventricular hypertrophy (LVH) [17-19] or with activation of the renin-angiotensin system [10-16]. The present investigation was carried out to define the impact of progressively increasing blood pressure levels on coronary blood flow in patients with established hypertension of diverse aetiologies and without angiographic evidence of coronary artery disease. 


\section{Materials and methods}

All 74 male subjects (age range $34-55$ years) were enrolled in this study after giving their informed consent. Fourteen subjects were normotensive (control group), 6 patients had isolated systolic hypertension due to mechanical factors (reduced aortic distensibility), 7 patients were affected by renovascular hypertension (RVH) and exhibited a chronically activated renin-angiotensin system (RAS) but neither ST-T abnormalities nor evidence of LVH on electrocardiographicechocardiographic examinations. Forty-seven patients with essential hypertension $(\mathrm{EH})$ were also enrolled. In 21 of them, the presence of LVH was assessed by electrocardiography and/or echocardiography. The presence of significant coronary artery disease was exluded in normotensive individuals by non-invasive diagnostics (maximum stress test according to Bruce protocol) and in all hypertensive patients by coronary arteriography.

\subsection{Haemodynamic studies}

All haemodynamic studies were performed in the morning without premedication. A number-5 French polyethylene catheter was introduced percutaneously (using local anaesthesia with 1\% lidocaine) into the brachial artery and advanced under fluoroscopy control to the ascending aorta for direct measurement of blood pressure. Phasic and mean arterial pressure (MAP) were recorded continuously during the study by means of a Statham strain-gauge transducer $(\mathrm{P} 23 \mathrm{db})$ connected to a Battaglia Rangoni recorder (model KO-380). An electrocardiographic tracing was recorded continuously during the haemodynamic studies. Coronary sinus blood flow (CBF) was measured by the intravascular Doppler technique [20]. A preshaped coronary sinus guide catheter (7F) was introduced through an antecubital vein and positioned using fluoroscopy in the coronary sinus. A 3F Doppler catheter (Millar inc. 20 $\mathrm{MHz}$ ) was then advanced until its tip transducer stuck out $5 \mathrm{~mm}$ above the distal end of the guide catheter. Stroke coronary volume (SCV) was calculated as the product of coronary sinus crosssectional area and time-velocity integral of pul- satile coronary sinus blood outflow. CBF resulted from the product of SCV and heart rate.

\section{Results}

Over a wide aortic diastolic pressure range (from about 85 to about $155 \mathrm{mmHg}$ ), resting $\mathrm{CBF}$ values were found to vary significantly in our study population. In normotensive subjects, mean aortic pressure, taken as an index of coronary perfusion pressure, ranged from 87 to $102 \mathrm{mmHg}$ and CBF from 150 to $176 \mathrm{ml} / \mathrm{min}$; in patients with isolated systolic hypertension (ISH), MAP ranged from 103 to $116 \mathrm{mmHg}$ and CBF from 190 to $213 \mathrm{ml} / \mathrm{min}$; in essential hypertensive patients without evidence of LVH, MAP varied from 105 and 142 and CBF from 170 and $223 \mathrm{ml} / \mathrm{min}$; in RVH patients, MAP ranged from 128 to 142 $\mathrm{mmHg}$ and CBF from 160 to $195 \mathrm{ml} / \mathrm{min}$; in

\section{FLOW-PRESSURE RELATIONSHIP} AT REST

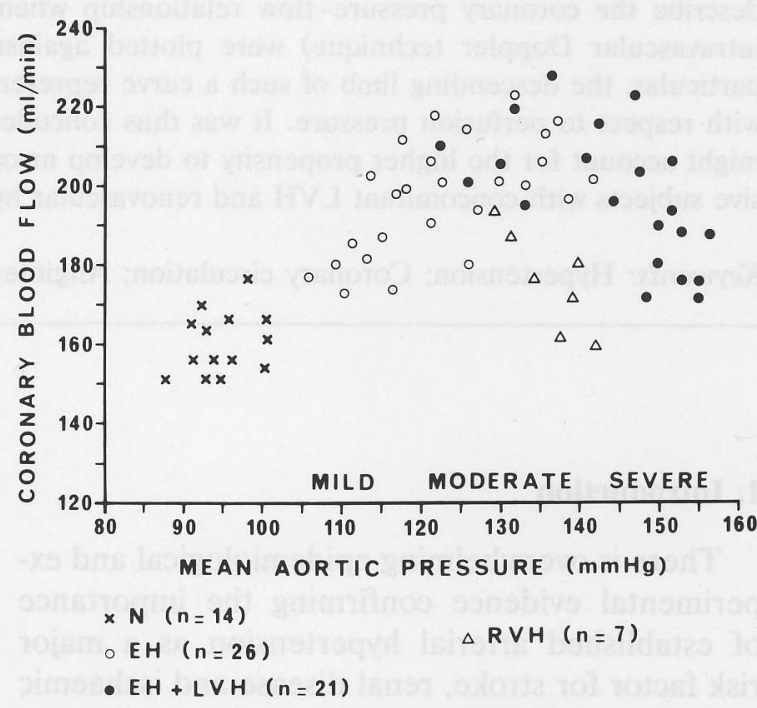

Fig. 1. Coronary pressure-flow relation in normotensive subjects $(\mathrm{N})$, in patients with isolated systolic hypertension (ISH), in patients with essential hypertension (EH) both with and without left ventricular hypertrophy (LVH) and in patients with renovascular hypertension (RVH). Over a wide aortic diastolic pressure range, CBF was found to vary significantly, the higher blood pressure levels being associated with a decrease, rather than an increase, in CBF. 
patients with $\mathrm{EH}$ and with concomitant $\mathrm{LVH}$, MAP ranged from 123 to $156 \mathrm{mmHg}$ and $\mathrm{CBF}$ from 170 to $228 \mathrm{ml} / \mathrm{min}$. In Fig. 1 the values for CBF measured in our study population are plotted against the corresponding values for mean aortic pressure. No changes in the pressure-flow relationship were found even if CBF was adjusted per unit anatomic cardiac mass as determined by 2D echocardiography [21].

\section{Discussion}

Like many other vascular beds, the coronary circulation exhibits a substantial capacity for autoregulation [22,23]. Under acute experimental conditions (Fig. 2), CBF is known to remain constant in the face of transitory changes in perfusion pressure between approximately 70 and 130 $\mathrm{mmHg}$. Because of the straight pressure-flow relation curve below 70 and above 130, considerable changes in $\mathrm{CBF}$ are expected to occur when these breaking points in the sigmoid pressureflow curve are exceeded. However, the precise role of coronary flow in coronary heart disease morbidity in patients with progressively increasing blood pressure levels remains to be clarified. According to our experimental data a Frank-Starling-like curve rather than a sigmoid curve seems to describe the coronary pressure-flow relation-

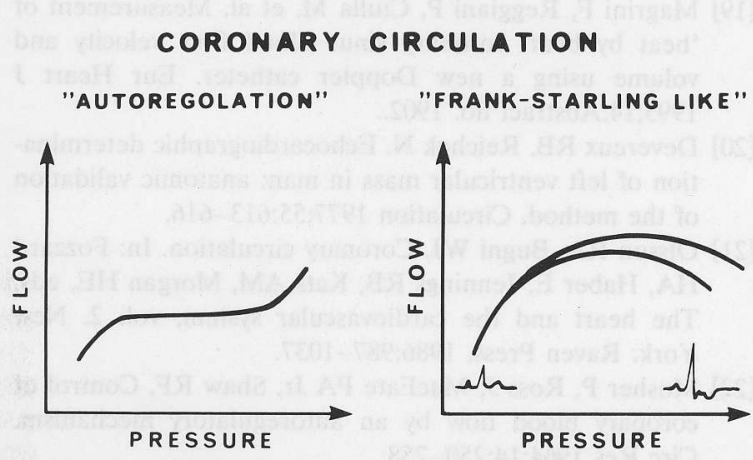

Fig. 2. The left panel shows the traditional pressure-flow relationship (coronary autoregulation) resulting from perfusion pressure-induced changes in coronary wall stretch under acute experimental conditions. The right panel depicts the hypothetical pressure-flow relationship operating in a chronic systemic multifactorial disease like arterial hypertension.

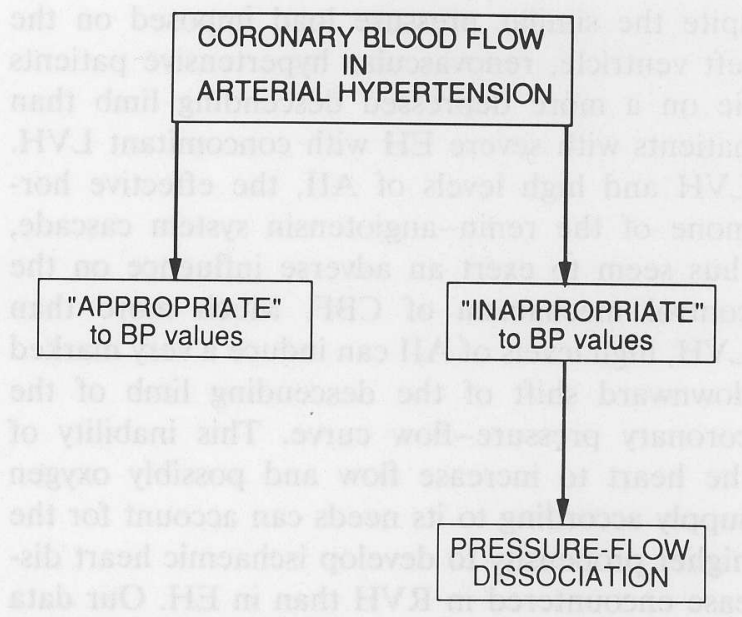

Fig. 3. Diagram relating the progressive increase in coronary perfusion pressure and coronary blood flow.

ship operating in a chronic, systemic disease like arterial hypertension (Fig. 2). Over a wide aortic diastolic pressure range, increases in $\mathrm{CBF}$ at rest are proportional to rises in coronary perfusion pressure until a critical point on the central, flat portion of the pressure-flow curve is reached. Further elevations in coronary perfusion pressure are associated with a decrease in CBF. As shown in Fig. 1, patients with ISH due to reduced aortic distensibility and mild essential hypertensive patients without LVH lie on the ascending limb of the curve. Under these clinical subsets, the changes in CBF match myocardial oxygen demand. Moderate essential hypertensive patients without LVH and some moderate essential patients with LVH rest on the central plateau of the curve. This early depression in the slope of the curve implies an initial inability to match further rises in myocardial oxygen demand at rest by the control mechanisms of myocardial perfusion. In this evolutionary phase the hypertensive disease is likely to be associated with the detection of ST-T abnormalities on the ECG. Both renovascular hypertensive patients and more severe essential hypertensive subjects with LVH definitely lie on the descending limb of the pressure-flow curve. Under these clinical circumstances, CBF is "inappropriately" low with respect to perfusion pressure (Fig. 3). An additional outstanding aspect deserving comment is the finding that de- 
spite the similar pressure load imposed on the left ventricle, renovascular hypertensive patients lie on a more depressed descending limb than patients with severe $\mathrm{EH}$ with concomitant $\mathrm{LVH}$. LVH and high levels of AII, the effective hormone of the renin-angiotensin system cascade, thus seem to exert an adverse influence on the control mechanism of CBF. Much more than $\mathrm{LVH}$, high levels of AII can induce a very marked downward shift of the descending limb of the coronary pressure-flow curve. This inability of the heart to increase flow and possibly oxygen supply according to its needs can account for the higher propensity to develop ischaemic heart disease encountered in RVH than in EH. Our data are in keeping with the hypothesis that besides coronary atherosclerosis, the abnormal coronary functional responses associated with $\mathrm{LVH}$ and AII "overload" may be responsible for myocardial ischaemia.

\section{References}

[1] Tarmsen P, Rosengren A, Tsipogianni A, Willalmsen L. Risk factors for stroke in middle aged men in Goteborg, Sweden. Stroke 1990;21:223-225.

[2] Fuji K, Sadoshima S, Okada Y. Central blood flow and metabolism in normotensive and hypertensive patients with transient neurological deficits. Stroke 1990;21:283286.

[3] Grunfeld O, Perelstein E, Simsolo R. Renal functional reserve and microalbuminuria in offspring of hypertensive patients. Hypertension 1990;15:257-260.

[4] Ordonez JD, Hiatt RA, Quesenberry CP. Epidemiological features of treated end-stage renal disease in a large prepaid health plan. Am J Publ Health 1990;80:47-50.

[5] Shulman NB, Ford CE, Hall WD. Prognostic value of creatinine and effect of treatment of hypertension on renal function. Results from the Hypertension Detection and Follow-up Program. Hypertension 1989;13(suppl I):I80-I-85.

[6] Gorlin R. Hypertension and ischemic heart disease: the challenge of the 1990's. Am Heart J 1991;121:671-686.

[7] Kannel WB. Contribution to the Framingham study to preventive cardiology. J Am Coll Cardiol 1990;15:206210.

[8] O'Kelly BF, Tubau JF, Szalchic J. Incidence and correlates of thallium defects in asymptomatic hypertensive patients. Circulation 1989;80(suppl II):536-540.
[9] Frolich ED. Coexistence of hypertension and coronary arterial disease. Hypertension 1985;10:473-475.

[10] Brunner HR, Laragh JH, Baer L, et al. Essential hypertension: renin and aldosterone, heart attack and stroke. N Engl J Med 1972;286:441-449.

[11] Alderman MH, Madhavan S, Oot WL, Cohen H, Sealey $\mathrm{JE}$, Laragh $\mathrm{JH}$. Association of the renin-sodium profile with the risk of myocardial infarction in patients with hypertension. N Engl J Med 1991;324:1098-1104.

[12] Magrini F, Reggiani P, Ciulla M, Meazza R, Fratianni G. Coronary haemodynamic effects of angiotensin II in mild essential hypertension in man. Clin Sci 1992;82:133-137.

[13] Magrini F, Roberts N, Macchi G, Mondadori C, Zanchetti A. Coronary haemodynamics following activation and inhibition of the renin-angiotensin system in mild hypertensive patients. J Cardiovasc Pharmacol 1987;10(suppl 5):S98-103.

[14] Magrini F, Reggiani P, Roberts N, Meazza R, Ciulla M, Zanchetti A. Effects of angiotensin and angiotensin blockade on coronary circulation and coronary reserve. Am J Med 1988;84(3A):55-60.

[15] Magrini F, Shimizu M, Roberts N, Fouad FM, Tarazi $\mathrm{RC}$, Zanchetti A, Converting enzyme inhibition and coronary blood flow. Circulation 1987;75(suppl I):I-168I-174.

[16] Magrini F, Reggiani P, Branzi G, Castriota F. Effects of angiotensin converting enzime inhibition on coronary blood flow. In: Sonnenblick EH, Laragh JH, Lesh M, eds. New frontiers in cardiovascular therapy: focus on angiotensin converting enzime inhibition. Amsterdam: Excerpta Medica-Elsevier Company, 1989;298-305.

[17] Marcus ML, Harrison DG, Chilian WM. Alteration in the coronary circulation in hypertrophied ventricles. Circulation 1987;75(suppl I):I-19-I-25.

[18] Marcus ML. Effects of cardiac hypertrophy on the coronary circulation. In: Marcus ML, ed. The coronary circulation in health and disease. New York: MacGraw Hill Books Co., 1983;285-306.

[19] Magrini F, Reggiani P, Ciulla M, et al. Measurement of 'beat by beat' coronary sinus blood flow velocity and volume using a new Doppler catheter. Eur Heart J 1993;14:Abstract no. 1902.

[20] Devereux RB, Reichek N. Echocardiographic determination of left ventricular mass in man: anatomic validation of the method. Circulation 1977;55:613-616.

[21] Olsson RA, Bugni WJ. Coronary circulation. In: Fozzard HA, Haber E, Jennings RB, Kats AM, Morgan HE, eds. The heart and the cardiovascular system, vol. 2. New York: Raven Press, 1986;987-1037.

[22] Mosher P, Ross J, MacFate PA Jr, Shaw RF. Control of coronary blood flow by an autoregulatory mechanism. Circ Res 1964;14:250-258.

[23] Hoffmann JIE. A critical view of coronary reserve. Circulation 1987;75 (Suppl I):I-6-I-25. 